\title{
Variations in the Electrical Resistivity of Vapour Grown Carbon Fibres by Effect of Successive Operations of Intake and Outgassing of Hydrogen
}

\author{
Cesar Mota ${ }^{1}$, Antonio Madroñero ${ }^{1}$, Jose Maria Amo ${ }^{1}$, Jose Ignacio Robla ${ }^{1}$, Mario Culebras $^{2} \&$ Andres Cantarero $^{2}$ \\ ${ }^{1}$ National Centre for Metallurgical Research (CENIM-CSIC), Madrid, Spain \\ ${ }^{2}$ Material Science Institute, University of Valencia, Valencia, Spain \\ Correspondence: Antonio Madroñero, National Centre for Metallurgical Research, Avda. Gregorio del Amo 8, \\ 28040, Madrid, Spain. Tel: 34-91-553-8900. E-mail: inmac09@gmail.com
}

Received: October 22, $2012 \quad$ Accepted: November 18, $2012 \quad$ Online Published: December 24,2012
doi:10.5539/jmsr.v2n1p163

\begin{abstract}
The aim of this work is to study the behaviour of Vapour Growth Carbon Fibres (VGCF) with different treatments after the intake and outgassing of hydrogen takes place.

The VGCFs are prepared via catalyzed decomposition of a mixture of hydrogen and methane. The catalyst was minute particles of iron. The fibre thickness was about 10 to 20 microns and they have a trunk-tree inner structure.

Two different treatments are tested to improve the properties of the as grown samples: a heat treatment under vacuum conditions and an acid etching with nitric acid. The desorption kinetics of the three type of samples is studied measuring the electrical resistivity during the hydrogen outgassing. As a result, the surface treatment with acid etching seems to be an efficient method to improve the kinetics of the hydrogen sorption in the first hydrogenation cycle.
\end{abstract}

Keywords: nanofibre, chemical vapour deposition, adsorption, desorption, electrical properties characterization, nanotechnology

\section{Introduction}

The current shortage of mineral energy sources and rising environmental pollution motivate many scientists all over the world to seek new non-polluting energy sources.

Hydrogen energy has attracted great attention because of its extraordinary advantages such as abundant supply and a concomitant reduction of green house gases emission. An efficient hydrogen storage media is desirable for widespread application of fuel cells and for the adoption of hydrogen as an energy source (Schlapbach \& Züttel, 2001).

Hydrogen storage at liquid state is considerably expensive; so the solution is to fabricate hydrogen reservoirs to store it (Schlapbach \& Züttel, 2001). In this way, great attention has been paid to hydrogen absorbent carbonaceous materials (Zubizarreta, Arenillas \& Pis, 2009), especially in the case of carbons that were fabricated from a mixture of hydrocarbon and hydrogen. In these cases, the carbonaceous materials as manufactured have a remarkable content of hydrogen (Michaelson, Ternyak, Akhvlediani, \& Hoffman, 2008) whose type of carbon-hydrogen bond depends on the process used to fabricate them (Butler \& Sumant, 2008).

In this work VGCFs (Vapour Grown Carbon Fibres) samples have been studied. The VGCFs are well known carbon microfilaments with the advantage of their reasonable cost (Beck, 1988). The data that exist in the literature with respect to this type of fibres show the advantageous effect of the treatment with nitric acid in the storage capacity of VGCFs (Vinke, van der Eijk, Verbree, Voskamp, \& Van Bekkum, 1994). They reach a hydrogen sorption capacity of $1.7 \%$ wt. of $\mathrm{H}_{2}$ which rises up to $2.1 \%$ wt. when the material is treated with nitric acid. However, no information about the required time to absorb and release hydrogen is provided (Shaijumon $\&$ Ramaprabhu, 2005).

The industrial application of VGCFs and other materials to be used as hydrogen reservoirs requires the control 
on the amount of hydrogen stored. To this purpose the electrical resistivity can be used since this physical parameter is related to the amount of hydrogen in the material. In fact, according to the literature, the resistivity decreases with the incorporation of hydrogen to the lattice of amorphous carbons (Voit, Evard \& Gabis, 2002; Dasgupta, Demichelis, \& Tagliaferro, 1991). Moreover, the monitoring of electrical resistivity appears in the literature as an advisable technique perfectly suitable for our purposes (Voit et al., 2002; Tóth, Garaguly, Tompa, Lovas, \& Varga, 1996) and more adequate than other physical parameters. For instance, it is well known that for the CVD diamond films (Rutledge \& Gleason, 1996) the value of the thermal conductivity affects the hydrogen content but, even though its influence is high for a content of $\mathrm{H}_{2}$ lower than $0.02 \mathrm{wt} \%$, for higher hydrogen content the influence is no longer appreciable. Besides, the measurement of the resistivity is easier.

In the present work we examine the progress of hydrogen desorption in VGCFs by means of the change in the electrical resistivity during the intake of hydrogen with different thermal treatments to modify the hydrogen content ( $\mathrm{Li}$ et al., 2008). Special attention has been paid to the behaviour of the VGCFs after the first charge-discharge cycle.

\section{Materials and Methods}

\subsection{Vapour Grown Carbon Fibres (VGCFs)}

The samples used in this study were VGCFs prepared via catalyzed decomposition of a gaseous hydrocarbon that produced a solid carbon deposit in the form of filaments. The germination and growth mechanisms are described according to a vapour-liquid-solid (VLS) process (Madroñero, 1995; Serp, Madroñero, \& Figueiredo, 1999) which consists in the formation of a liquid drop of coronene that absorbs hydrogen from the atmosphere composed by a mixture of hydrogen and a hydrocarbon gas. The solidification of this drop produces the carbonaceous VGCF that contains a significant amount of hydrogen (Madroñero \& Verdú, 1995).

VGCFs used in this study were produced in a furnace consisting of a horizontal mullite tube of $80 \mathrm{~mm}$ of internal diameter and $1 \mathrm{~m}$ length. The reactor was externally powered by electrical heating elements controlled by means of a temperature programmer CN616TC1, manufactured by Omega ${ }^{\mathrm{TM}}$. The output of the programmer controlled a solid state relay SSR330DC25, made also by Omega ${ }^{\mathrm{TM}}$.

Reactants were Hydrogen Premier Plus X50S, 99.999\% purity, and Methane X50S, 99.995\% purity, both supplied by Carburos Metalicos ${ }^{\mathrm{TM}}$. The mixture of both gases and the flow rate control was performed by a mass flow controller AWS-Digital, manufactured by Witt ${ }^{\mathrm{TM}}$. The reactants were introduced in the reactor without any pre-treatment (deoxygenating, preheating).

The composition of hydrocarbon was catalysed by an iron catalyst. The fibres were grown on a substrate made of Grafoil ${ }^{\circledR}$ (Le Carbone Lorraine ${ }^{\mathrm{TM}}$ ). Onto this substrate, an ethanolic solution of $0.025 \mathrm{M}$ of nonahydrated ferric nitrate $\left(\mathrm{Fe}\left(\mathrm{NO}_{3}\right)_{3} \cdot 9 \mathrm{H}_{2} \mathrm{O}\right)$ was nebulised.

The ethanol was evaporated by means of drying in an oven at $373 \mathrm{~K}$ for 10 minutes. Then, the substrate was covered by many diminute grains of the ferric nitrate. The substrate was situated in the centre of the mullite tube.

The production process consisted of three stages. The first one was carried out in an atmosphere of pure hydrogen at a heating rate of $20 \mathrm{~K} / \mathrm{min}$ until $1173 \mathrm{~K}$ was reached. Then, the temperature was stabilised during 5 minutes. In the third stage, the atmosphere was changed to a mixture of $70 \%$ of hydrogen and $30 \%$ of methane with a flow rate of $950 \mathrm{~cm}^{3} \cdot \mathrm{min}^{-1}$. The heating rate was $15 \mathrm{~K} / \mathrm{min}$ until $1425 \mathrm{~K}$ was achieved. This process temperature was then kept at $1425 \mathrm{~K}$ for 40 minutes.

Finally, the furnace was cooled down under an atmosphere of pure Ar.

The microstructure of this type of fibres has already been described, showing two carbonaceous phases (Madroñero, Verdú, Issi, Martín-Benito Romero, \& Barba, 1998; Madroñero, Ariza, Verdú, Brandl, \& Barba, 1996). At the microscopic level, the inner grain shows trunk-tree morphology because during the filament formation the carbon deposit forms concentric cylindrical shells (Madroñero et al., 1998). In the submicroscopic level, it is observed the existence of hard carbonaceous spangles surrounded by amorphous material (Madroñero et al., 1996).

Measurements of electrical resistivity were performed in three types of samples, depending on the preparation procedure:

- Sample A: Ex-methane as grown. The diameter of the fibres is $16.8 \mu \mathrm{m}$.

- Sample B: Ex-methane grown fibres with further annealing at $1473 \mathrm{~K}$ during $2 \mathrm{~h}$ in vacuum conditions with a residual atmosphere of $\operatorname{Ar}\left(0.5 \times 10^{-3} \mathrm{bar}\right)$. The diameter of the fibres is $16.6 \mu \mathrm{m}$. 
- Sample C: Ex-methane grown fibres subjected afterwards to a superficial acid treatment in $\mathrm{HNO}_{3}$ for 24 hours. After the acid treatment the fibres were washed in distilled water several times in order to eliminate completely the acid. Then, they were dried in a stove at $373 \mathrm{~K}$ during 4 hours. The acid treatment is described in (Vinke et al., 1994; Takagi, Soneda, Hatori, Zhu, \& Lu, 2007). The diameter of the fibres in the case of sample C is 19.1 $\mu \mathrm{m}$.

The acid treatment is expected to activate the surface promoting changes in the kinetics of hydrogen storage (Zhang et al., 2003).

\subsection{Electrical Resistivity Measurements}

The resistivity measurements were carried out during the hydrogenation/dehydrogenation process using the four probe method (Hájek, Veselýa, \& Cieslara, 2007). The sample fibres were mounted in a resin frame sheet reinforced with glass fibre. The fibres were attached to the frame by four drops of conductive silver paint (CircuitWorks Conductive Epoxy CW2400) that were used as electrodes. The length of each fibre was established by the frame and the distance between the drops. The thickness of each carbon filament was measured using the diffraction of a laser beam $(\lambda=642 \mathrm{~nm})$ considering the Fraunhofer diffraction model (Madroñero \& Merino, 1998). The accuracy of the measurements of the diameter of the fibres was $\pm 0.02 \mu \mathrm{m}$, which permits an accuracy of the resistivity measurements of $0.1 \%$.

The frame with the samples was placed inside a stainless steel tube of an inner diameter of $1 \mathrm{~cm}$ which constitutes the working chamber. The system was purged with a slight current of hydrogen to sweep atmospheric gases away. The hydrogen (Hydrogen Premier Plus X50S, purity 99.999\%, Carburos Metalicos ${ }^{\circledR}$ ) was supplied from a gas cylinder.

The charge process by adsorption of hydrogen was carried out in a hydrogen atmosphere with a pressure up to 200 bars. The discharge process was achieved establishing a pressure of 1 bar in the chamber. The resistivity of the carbonaceous filaments was monitored during both processes using a measurement system model SR830 DSP made by Stanford Research Systems ${ }^{\circledR}$.

A scanning electron microscope (SEM) Hitachi S2100, has been used to observe the morphology of selected fibres.

\section{Results and Discussion}

\subsection{Relationship between Electrical Resistivity and Hydrogen Content}

As mentioned above, the electrical resistivity of carbon fibres depends on their hydrogen content, as it has been described for amorphous carbons (Dasgupta et al., 1991) and crystalline carbons (Liu et al., 2007). In fact, it is usual to track the hydrogenation process through the measurement of the electrical resistivity in metallic compounds (Tóth, Garaguly, Trompa, Lovas \& Varga, 1996). It has been proposed that this variation occurs because the carbon bonds broken during desorption process create traps for the free electron carriers which are neutralised in the hydrogen intake process. This is in agreement with our experimental results, where the resistivity decreases during the hydrogen adsorption and increases during the desorption process (Figures 1-3).

Looking for an easy interpretation of the plots, in the following figures the fitting is also included, for comparison purposes. 


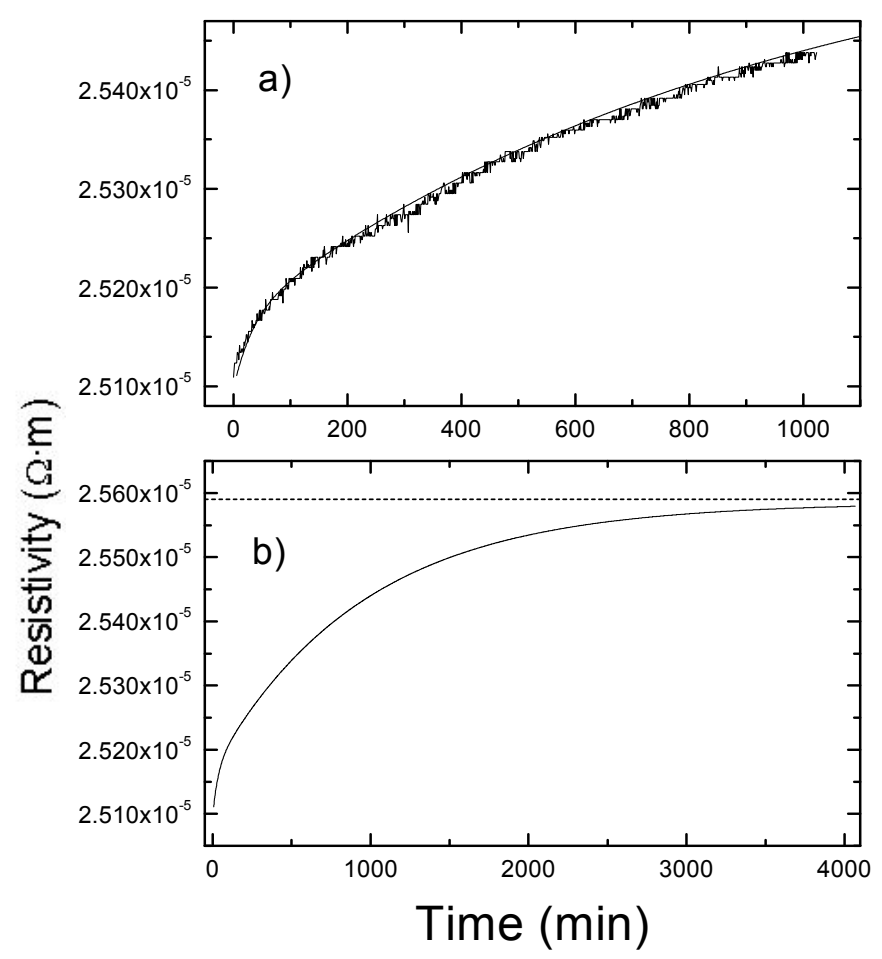

Figure 1. a) Experimental data and b) fitting of the resistivity data acquired during the first discharge process carried out in the as grown material (sample A)

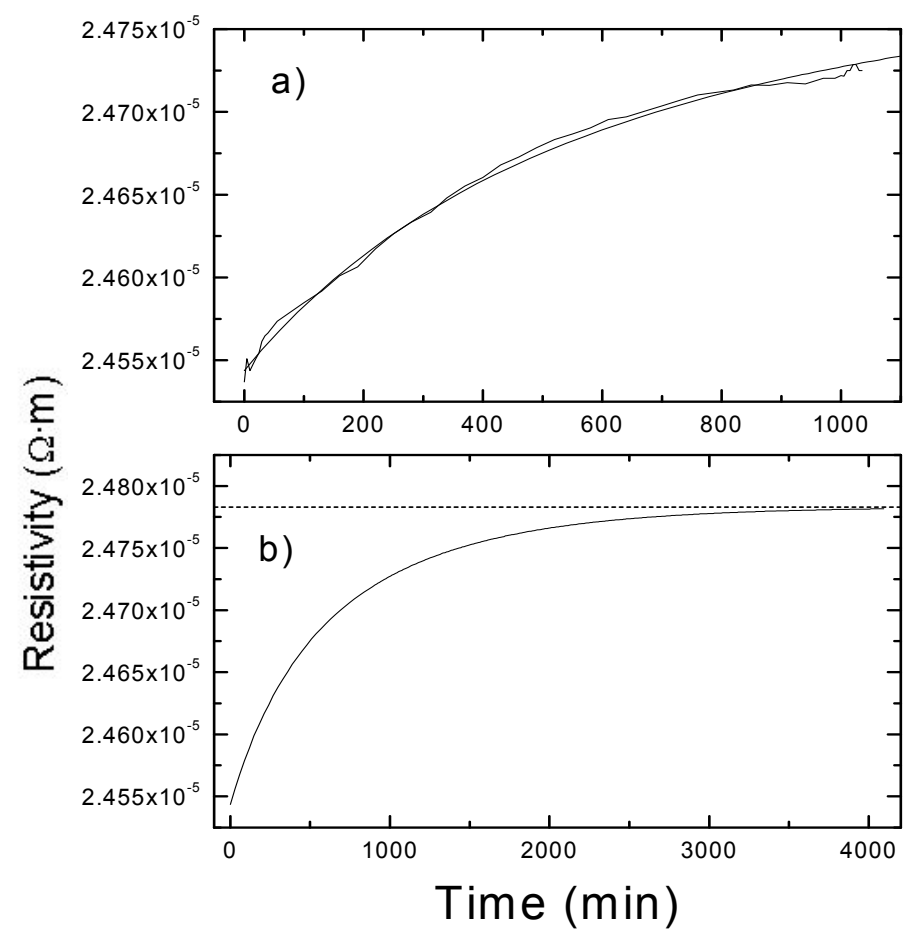

Figure 2. a) Experimental data and b) fitting of the resistivity data acquired during the first discharge process carried out in sample B 


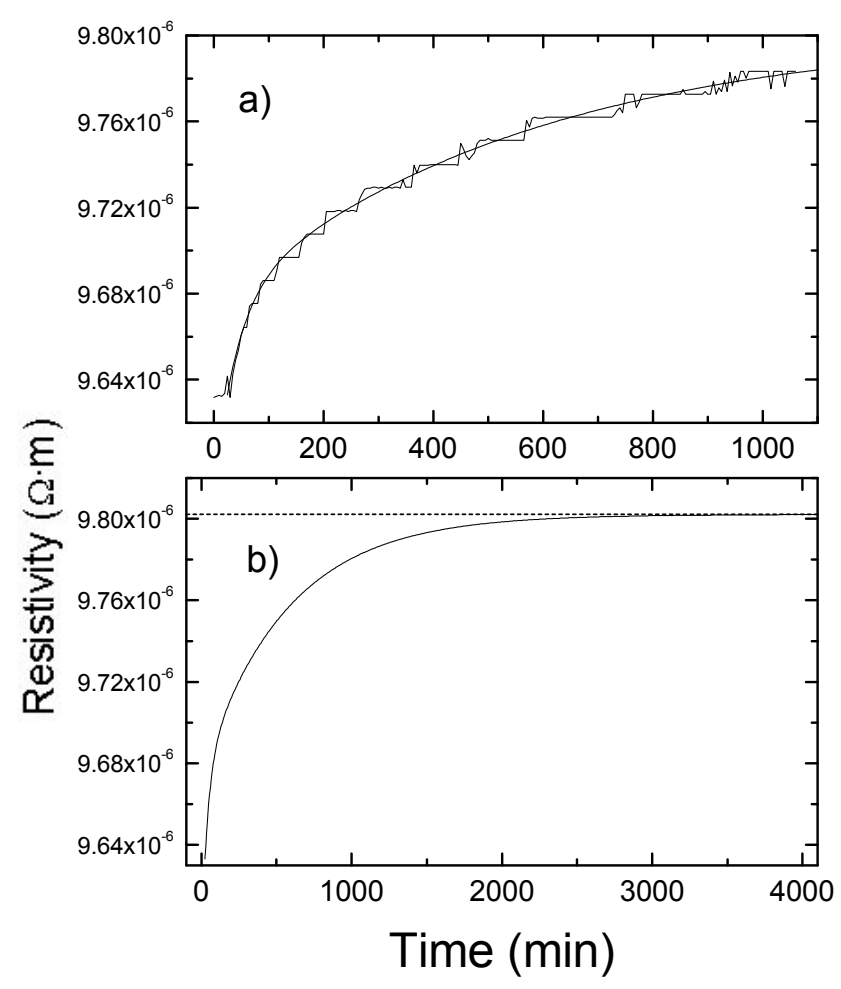

Figure 3. a) Experimental data and b) fitting of the resistivity data acquired during the first discharge process carried out in sample $\mathrm{C}$

\subsection{Mathematical Fitting}

In order to compare the effect of the different treatments in the VGCFs, the experimental results were fitted to a mathematical expression.

It is known that VGCFs shows a semiconductive character (Liu, Ji, Zhang, Yang, \& Xu, 2008). This is equivalent to say that the electrical resistivity of these fibres is very sensitive to the number of electrical carriers. Therefore, we can follow the model of Romanenko et al. (2007) based onto the influence of the absorption of hydrogen in the nanocavities of Multi-Walled Carbon Nanotubes (MWCNT) on their electrical resistivity. These MWCNTs have a similar grain to the fibres studied in the present work.

As in these fibres two types of nanocavities exist, it is necessary to admit that the adsorbed hydrogen can be fixed on a surface pore or in inner nanocavities. Therefore, in the present case the proper mathematical model would be an expression constituted by the sum of two similar curves with two different energy figures.

Hence, the following empirical expression was chosen to carry out the fitting of the results:

$$
\rho(t)=\rho_{0}+T_{1}(t)+T_{2}(t)
$$

Where $\rho$ is the electrical resistivity, $t$ is the time, and $T_{1}$ and $T_{2}$ correspond to the expressions:

$$
\begin{aligned}
& T_{1}(t)=\mathrm{R}_{1} \cdot\left(1-\exp \left(-\mathrm{t} / \mathrm{t}_{1}\right)\right) \\
& T_{2}(t)=\mathrm{R}_{2} \cdot\left(1-\exp \left(-\mathrm{t} / \mathrm{t}_{2}\right)\right)
\end{aligned}
$$

$R_{1}, R_{2}$ and $\rho_{0}$ are constants related to the mechanism of hydrogen fixation and the effect of the structure of the carbon crystallographic plains, while $t_{1}$ and $t_{2}$ are representatives of the time taken in the charge/discharge process.

The Equation (1) is chosen with two terms because it is frequent that the hydrogen atoms adsorbed in carbons are bonded with two different energies. For instance, the hydrogen captured in graphite mechanically milled is desorbed through two thermal windows around $650 \mathrm{~K}$ and $900 \mathrm{~K}$ (Orimo, Matsushima, Fujii, Fukunaga, \& Majer, 
2001).

The resistivity measurements carried out during the hydrogen intake and outgassing processes in the three samples, A, B and C, are shown in Figures 1a, 2a and 3a, respectively, together with their respective fitting curves. As it can be seen, all the fittings of the evolution of the resistivity with expression (1) were very satisfactory in all cases.

In order to check that the changes in the resistivity were due to the hydrogen intake and not caused by mechanical deformations in the electric contacts due to the pressurization of the gas, the process was repeated using helium instead of hydrogen. As a result, no variation in the resistivity was obtained, so the changes in the resistivity during the process can be directly associated to the effect of the hydrogen adsorption and its release.

\subsection{Hydrogen Outgassing Process: Electrical Resistivity and Discharge Time}

The application of the expression (1) to the discharge process of sample A gives the following result:

$$
\rho_{A}(t)=\rho_{A 0}+T_{1 \mathrm{~A}}+T_{2 \mathrm{~A}}
$$

Where:

$$
\begin{gathered}
\rho_{A 0}=22.45 \cdot 10^{-6} \Omega \cdot \mathrm{m} \\
T_{1 A}=2.66 \cdot 10^{-6} \cdot\left(1-\exp \left(-\frac{\mathrm{t}+89}{33.51}\right)\right) \\
T_{2 A}=4.73 \cdot 10^{-7} \cdot\left(1-\exp \left(-\frac{t+89}{947.70}\right)\right)
\end{gathered}
$$

Given the exponential behaviour, let us define the time of discharge when the $99 \%$ of the resistivity increase has been achieved. Applying this criterion to the results obtained in sample A, the time necessary for a complete discharge would be about 4000 minutes ( $\sim 67$ hours).

The equation of the asymptote of the expression (1) is:

$$
\Psi=\rho_{0}+R_{1}+R_{2}
$$

If we consider Equation (4), the resistivity of the sample after a complete discharge process is $\Psi_{\mathrm{A}}=2.559 \cdot 10^{-5}$ $\Omega \cdot \mathrm{m}$.

Proceeding similarly with sample B, it was also checked that the increase of the pressure did not affect the resistivity under inert atmosphere.

The response of the electrical resistivity during the hydrogen discharge process has been fitted to expression (1) (see Figure 2). In this case, the duration of the discharge process is 3692 minutes ( $\sim 62$ hours) and a final resistivity is $\Psi_{\mathrm{B}}=2.478 \cdot 10^{-5} \Omega \cdot \mathrm{m}$.

Desorption time of sample B is slightly lower than that of sample A $(\sim 8 \%)$, which seems to be of little advantage concerning the time of discharge. Moreover, since the resistivity values of both samples are very similar, we can establish that the annealing process has produced little alterations with no significant influence on the hydrogen release.

Finally, regarding the effect of the nitric acid (sample C), we have to highlight that the SEM images taken before (Figures $4 \mathrm{a}$ and $4 \mathrm{c}$ ) and after the treatment (Figures $4 \mathrm{~b}$ and $4 \mathrm{~d}$ ) shows that the acid affects only to the surface of the fibres as intended, remaining the core-shell structure of the as-grown fibres. The Figure 4a corresponds to the SEM characterization of this type of VGCFs previously described in Madroñero, Ariza and Verdu (1996). 


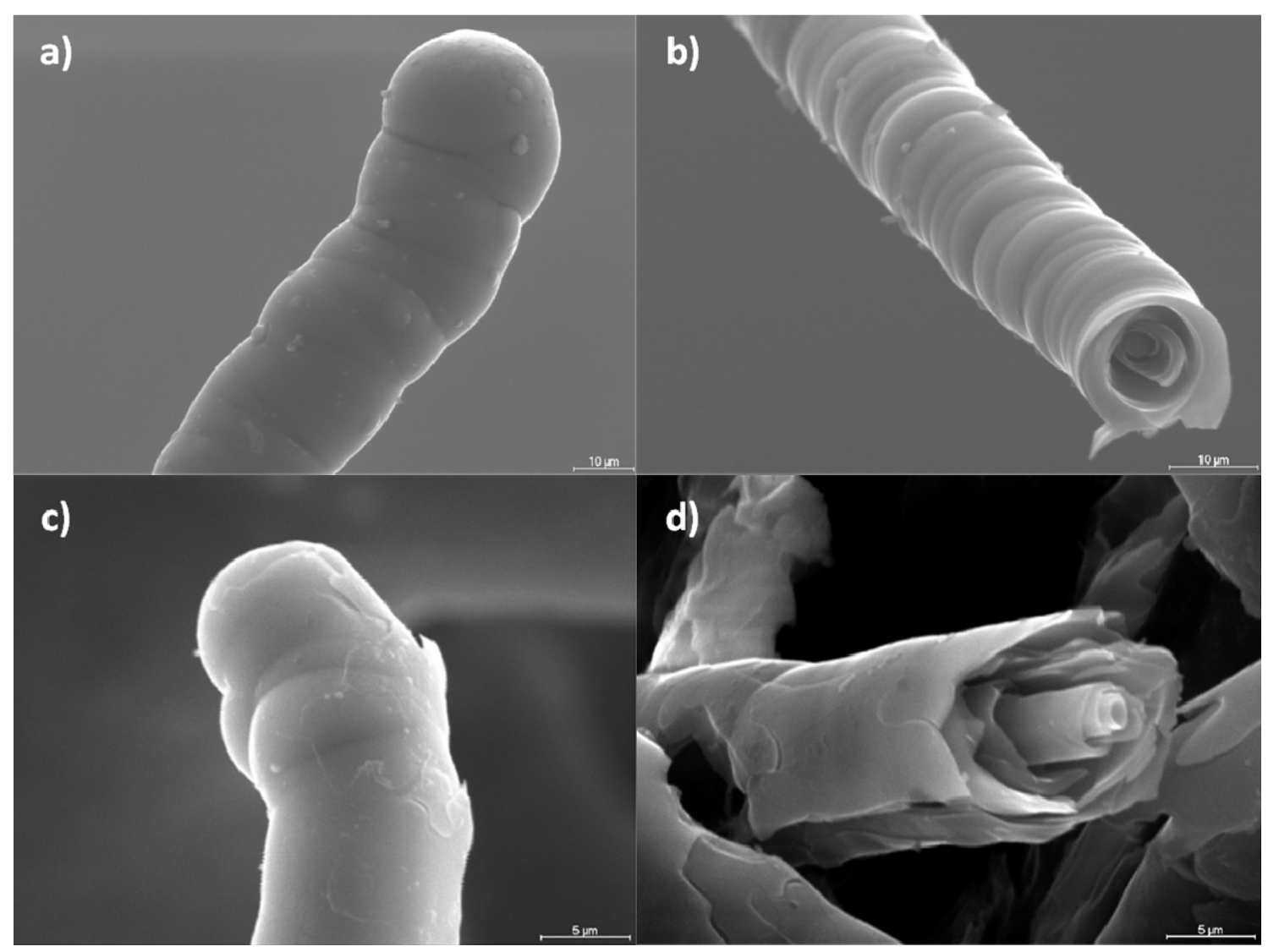

Figure 4. As-grown fibre a) tip, and b) section showing "trunk tree" structure Acid treated fibre c) tip and d) section showing the "trunk-tree" structure

The expression of the fitting of the discharge process of sample $\mathrm{C}$ is the following:

$$
\begin{gathered}
\rho_{C}(t)=\rho_{C 0}+\mathrm{T}_{1 \mathrm{C}}+\mathrm{T}_{2 \mathrm{C}} \\
\rho_{C 0}=4.89 \cdot 10^{-3} \Omega \cdot \mathrm{m} \\
T_{1 C}=2.72 \cdot 10^{-7} \cdot\left(1-\exp \left(-\frac{\mathrm{t}+428}{563.66}\right)\right) \\
T_{2 C}=4.9 \cdot 10^{-3} \cdot\left(1-\exp \left(-\frac{t+428}{39.23}\right)\right)
\end{gathered}
$$

As a result, a discharge time of 2300 minutes ( $\sim 38$ hours) is obtained, which means, as intended, that the treatment with nitric acid activates the surface and shortens the outgassing kinetics of hydrogen a $43 \%$. The value of the resistivity after the complete discharge process is $\Psi_{\mathrm{C}}=9.802 \cdot 10^{-6} \Omega \cdot \mathrm{m}$ which is lower than those obtained in samples A and B.

\subsection{Second Charge-Discharge Cycle}

Although the reduction in the discharge time is remarkable, it is still slower than that the discharge time exhibited by other carbon-based materials, as it is the case of Carbon Nanotubes (CNT), which shows a complete discharge in less than $500 \mathrm{~min}$ (C. Liu, Fan, M. Liu, Cong, \& Cheng, 1999). Anyway, Liu et al. (1999) do not show the behaviour of these CNTs after the first discharge process. In order to test the response of the acid treatment in successive charge and discharge processes a second cycle was carried out in sample $\mathrm{C}$, as well as in the as-grown material (sample A), for comparison purposes. Both results can be found in Figures 5 and 6 , respectively. 


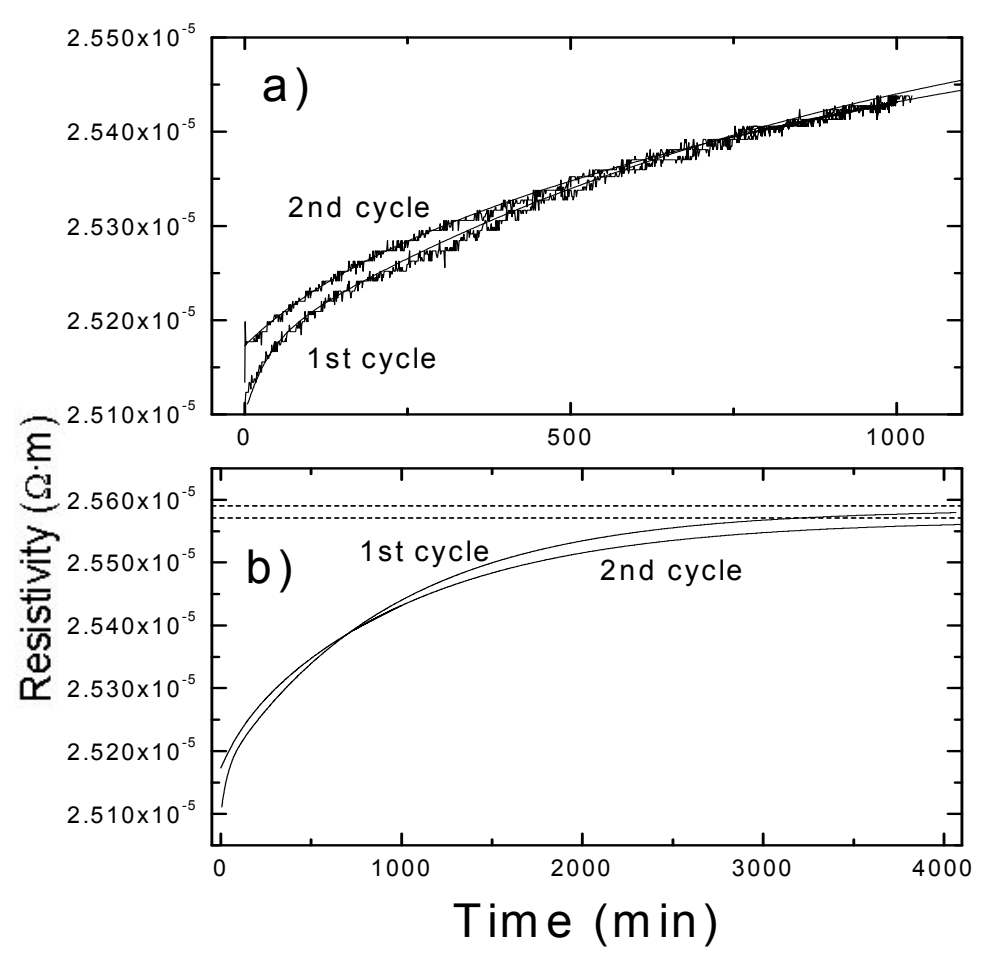

Figure 5. a) Experimental data and b) fitting of the resistivity data acquired during the first and second discharge processes carried out in the as grown material (sample A)

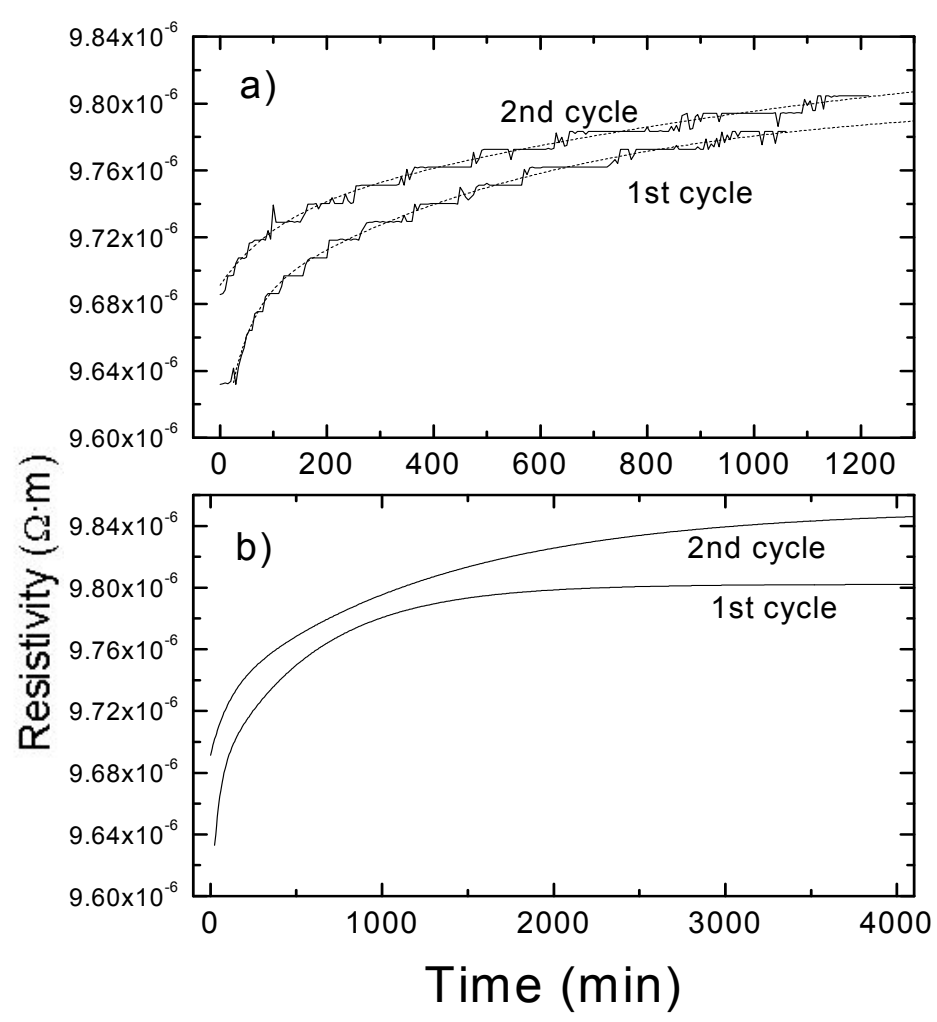

Figure 6. a) Experimental data and b) fitting of the resistivity data acquired during the first and second discharge processes carried out in sample $\mathrm{C}$ 
Applying the Equation (1) to the second discharge process carried out in sample A, a discharge time of $\sim 4700$ min ( $\sim 78$ hours) is obtained, which is a $\sim 17 \%$ longer than the one obtained in the first cycle. The value of the resistivity at the end of the discharge process, however, remains almost the invariable $\left(\Psi_{\mathrm{A}}=2.556 \cdot 10^{-5} \Omega \cdot \mathrm{m}\right)$. This invariance of the final resistivity value is an indicator that, although the kinetics of desorption is slower, the hydrogen storage capacity of the material remains the same.

Regarding the sample C (Figure 6), a discharge time of $5020 \min$ ( $\sim 33$ hours) is obtained for the second cycle, which is a factor 2 higher than the discharge time calculated for the first one. The value of the final resistivity is essentially the same as that obtained in the previous cycle $\left(\Psi_{\mathrm{C}}=9.851 \cdot 10^{-6} \Omega \cdot \mathrm{m}\right)$. In this case, as it occurred with sample A, the constant value of the final resistivity points to the same hydrogen absorption. However, it is clear that although the effect of the acid treatment in the VGCF remains in further cycling as shown by the lower resistivity values with respect to sample A (as grown material), the advantage of a reduced discharge time is lost after the first desorption process.

In our opinion it is important to highlight that all these measurements and therefore the desorption processes provide the behaviour of VGCFs at room temperature. This is a significant fact in order to make a possible forecast of the use of these adsorbent materials in hydrogen reservoirs for automotive industry or for large installations involved in energy production.

The reduced time of discharge of sample $\mathrm{C}$ with respect to sample $\mathrm{A}$ in the first cycle is a very interesting result, which would be suitable in applications where an adsorbent material is needed to work as a one-use industrial hydrogen reservoir, for instance, an emergency kit constituted by an absorbed hydrogen tank plus a fuel cell to work as a reservoir of electric power.

\subsection{Adsorption Mechanism Discussion}

The model of the adsorption of hydrogen on VGCFs was shown in a previous work (Madroñero, Ariza, \& Verdú, 1995). The results of the present study permit to obtain additional information on the adsorption kinetics of the hydrogen in the studied fibres.

In the literature two basic mechanisms are described that explain the localization of the hydrogen in carbonaceous solids:

On the one hand, it is well known that the pores in the surface produced by the finishing treatment enhances $\mathrm{C}-\mathrm{H}_{2}$ interactions and, thus, increases the $\mathrm{H}_{2}$ storage capacity (Yushin, Dash, Jagiello, Fisher, \& Gogotsi, 2006). For this reason, the fibres of the sample $\mathrm{C}$ show a rapid adsorption on its surface.

On the other hand, the atomic hydrogen can react with the graphene plains, with a transformation of a highly conductive semimetal into an insulator (Elias et al., 2009). Accordingly, it is found that after intercalation atomic hydrogen is stored among graphene layers in $\mathrm{H}_{2}$ gas form, captured inside graphene blisters (Waqar, 2007).

The same behaviour as in graphene is observed in benzene and coronene (Ma, Michaelis, \& Alfè, 2011), which is the main constituent of the fibres studied in the present work (Madroñero, 1995). These processes determine the adsorption and desorption of hydrogen (Waqar, 2007).

\subsection{Bulk and Surface Hydrogen}

If we compare the rate of adsorption when the intake of hydrogen starts $\left(\rho^{\prime}(t=0)\right)$, that is to say that the different slope of the tangent to the plot in Figures $1 \mathrm{~b}$ and $1 \mathrm{c}$ points out that $\rho$ ' is an adequate parameter to represent the intensity of the physical mechanisms that controls the hydrogen diffusion.

The derivative of the Equation (4) is:

$$
\rho_{A}^{\prime}(t=0)=T_{1 A}^{\prime}(t=0)+T_{2 \mathrm{~A}}^{\prime}(t=0)
$$

Where:

$$
\begin{gathered}
T_{1 A}^{\prime}(t=0)=2.36 \cdot 10^{-4} \Omega \cdot \mathrm{m} \cdot \mathrm{s}^{-1} \\
T_{2 A}^{\prime}(t=0)=3.94 \cdot 10^{-5} \Omega \cdot \mathrm{m} \cdot \mathrm{s}^{-1}
\end{gathered}
$$

In the same way, the derivative of Equation (8) is: 


$$
\rho_{C}^{\prime}(t=0)=T_{1 C}^{\prime}(t=0)+T_{2 C}^{\prime}(\mathrm{t}=0)
$$

Where:

$$
\begin{gathered}
T_{1 C}^{\prime}(t=0)=1.16 \cdot 10^{-4} \Omega \cdot \mathrm{m} \cdot \mathrm{s}^{-1} \\
T^{\prime}{ }_{2 C}(t=0)=2.097 \Omega \cdot \mathrm{m} \cdot \mathrm{s}^{-1}
\end{gathered}
$$

The comparison of the Equations (16) and (18) shows that $T_{1}$ are similar for both samples, but $T_{2}$ is not. For this it is reasonable to suppose that $\mathrm{T}_{1}$ represents to the hydrogen loaded in the bulk of the fibre and $\mathrm{T}_{2}$ and represents the hydrogen located in the surface pores. The same order of magnitude between (14) and (17) is due to in the bulk of fibre the confinement of the hydrogen takes place in the coronene blisters. This is similar for the samples A and $\mathrm{C}$.

We believe that the used technique consisting of the monitoring of the electrical resistivity is more adequate than the conventional practice of evaluating the outgassing of hydrogen by Thermogravimetric Analysis (TGA); in Broom (2007) the disadvantages of TGA for this kind of materials are described.

It would be interesting to continue with future studies about the capacity to store hydrogen in the groups of materials that are candidates for these applications (organometallic frameworks, carbonaceous materials, metal hydrides, etc). It is especially important to consider the speed of the charge and discharge and the variation of the storage capacity in successive cycles. This line of research is especially interesting in the way towards hydrogen economy because the most relevant and unsolved milestones are the kinetics of intake and outgassing of hydrogen in solid adsorbents and their repeatibility of charge-discharge cycles.

\section{Conclusion}

According to the results of the present work, it is possible to conclude that:

- The described annealing process does not affect either the speed of the discharge or the storage capacity appreciably.

- The acid treatment modifies the peripheral region which improves highly the kinetics of the discharge in the first cycle.

- This work agrees with the existence of two types of nanocavities where the hydrogen can be located. For this reason, the fitting curve that represents the variation of the charge is constituted by two components.

- The significant duration of the discharge processes suggests that if Vapour Grown Carbon Fibres were used as industrial hydrogen storages, they would be suitable for large storages included in great energy production installations. Contrarily, the discharge time turns out to be excessive looking to the application in vehicles/automotive industries.

\section{Acknowledgements}

We would like to acknowledge support from the Spanish Ministry of Research and Innovation MICINN, with a budget of the CONSOLIDER project assigned as NANOTHERM CSD2010-00044.

\section{References}

Beck, S. (1988). How to Apply Advanced Composites Technology. In Proceedings of the Fourth Annual Conference on Advanced Composites (pp. 463-473). ASM International. Dearborn, Michigan, USA (13-15 September).

Broom, D. P. (2007). The accuracy of hydrogen sorption measurements on potential storage materials. International Journal of Hydrogen Energy, 32(18), 4871-4888. http://dx.doi.org/10.1016/j.ijhydene.2007.07.056

Butler, J. E., \& Sumant, A. V. (2008). The CVD of Nanodiamond Materials. Chemical Vapor Deposition, 14(7-8), 145-160. http://dx.doi.org/10.1002/cvde.200700037

Dasgupta, D., Demichelis, F., \& Tagliaferro, A. (1991). Electrical conductivity of amorphous carbon and amorphous hydrogenated carbon. Philosophical Magazine B, 63(6), 1255-1266. http://dx.doi.org/10.1080/13642819108205558 
Elias, D. C., Nair, R. R., Mohiuddin, T. M. G., Morozov, S. V., Blake, P., Halsall, M. P., ... Novoselov, K. S. (2009). Control of Graphene's Properties by Reversible Hydrogenation: Evidence for Graphane. Science, 323(5914), 610-613. http://dx.doi.org/10.1126/science.1167130

Hájek, M., Veselýa, J., \& Cieslara, M. (2007). Precision of electrical resistivity measurements. Materials Science and Engineering A, 462(1-2), 339-342. http://dx.doi.org/10.1016/j.msea.2006.01.175

Li, X., Yuan, G., Westwood, A., Zhang, H., Dong, Z., Brown, A., ... Rand, B. (2008). The Preparation and CVD Densification of Multi-walled Carbon Nanotube Felt Synthesized by a Catalytic CVD Method. Chemical Vapor Deposition, 14(1-2), 40-45. http://dx.doi.org/10.1002/cvde.200706634

Liu, C., Fan, Y. Y., Liu, M., Cong, H. T., Cheng, H. M., \& Dresselhaus, M. S. (1999). Hydrogen Storage in Single-Walled Carbon Nanotubes at Room Temperature. Science, 286(5442), 1127-1129. http://dx.doi.org/10.1126/science.286.5442.1127

Liu, C., Xiao, X., Wang, J., Shi, B., Adiga, V. P., Carpick, R. W., ... Auciello, O. (2007). Dielectric properties of hydrogen-incorporated chemical vapor deposited diamond thin films. Journal of Applied Physics, 102(7), 074115 (7 pages). http://dx.doi.org/10.1063/1.2785874

Liu, X., Ji, W., Zhang, Y., Yang, Y., \& Xu, B. (2008). The morphology and electrical resistance of long oriented vapor-grown carbon fibers synthesized from coal pitch. Carbon, 46, 154-158. http://dx.doi.org/10.1016/j.carbon.2007.11.010

Ma, J., Michaelis, A., \& Alfè, D. (2011). Binding of hydrogen on benzene, coronene, and graphene from quantum Monte Carlo calculations. Journal of Chemical Physics, 134(13), 134701(6 pages). http://dx.doi.org/10.1063/1.3569134

Madroñero, A. (1995). Possibilities for the vapour-liquid-solid model in the vapour-grown carbon fibre growth process. Journal of Materials Science, 30(8), 2061-2066. http://dx.doi.org/10.1007/BF00353034

Madroñero, A., Ariza, E., \& Verdú, M. (1995). Adsorption of hydrogen in carbon fibres made from polyacrylonitrile precursor, and vapour grown. European Journal of Solid State and Inorganic Chemistry, 32(11), 1115-1127.

Madroñero, A., Ariza, E., \& Verdú, M. (1996). A model of duplex structure for short vapour-grown carbon fibres. Journal of Materials Chemistry, 6(6), 1059-1065. http://dx.doi.org/10.1039/jm9960601059

Madroñero, A., Ariza, E., Verdú, M., Brandl, W., \& Barba, C. (1996). Some microstructural aspects of vapour-grown carbon fibres to disclose their failure mechanisms. Journal of Materials Science, 31(23), 6189-6193. http://dx.doi.org/10.1007/BF00354437

Madroñero, A., \& Merino, C. (1998). Some geometrical singularities in the characterization of vapor grown carbon fibers using laser diffraction technique. Materials Research Bulletin, 33(10), 1503-1515. http://dx.doi.org/10.1016/S0025-5408(98)00144-5

Madroñero, A., \& Verdú, M. (1995). Hydrogen content evaluation in Vapour-grown carbon fibres by SIMS. Carbon, 33(3), 247-251. http://dx.doi.org/10.1016/0008-6223(94)00139-Q

Madroñero, A., Verdú, M., Issi, J. P., Martín-Benito Romero, J., \& Barba, C. (1998). Study by a modified scanning electron microscope fractography of hydrogenation process in vapour grown carbon fibres. Journal of Materials Science, 33(8), 2079-2085. http://dx.doi.org/10.1023/A:1004362901697

Michaelson, S., Ternyak, O., Akhvlediani, R., \& Hoffman, A. (2008). The Impact of Diamond Grain Size on Hydrogen Concentration, Bonding Configuration, and Electron Emission Properties of Polycrystalline-Diamond Films. Chemical Vapor Deposition, 14(7-8), 196-212. http://dx.doi.org/10.1002/cvde.200706650

Orimo, S., Matsushima, T., Fujii, H., Fukunaga, T., \& Majer, G. (2001). Hydrogen desorption property of mechanically prepared nanostructured graphite. Journal of Applied Physics, 90(3), 1545 (5 pages). http://dx.doi.org/10.1063/1.1385362

Romanenko, A. I., Anikeeva, O. B., Kuznetsov, V. L., Buryakov, T. I., Tkachev, E. N., \& Usoltseva, A. N. (2007). Influence of helium, hydrogen, oxygen, air and methane on conductivity of multiwalled carbon nanotubes. Sensors and Actuators A, 138, 350-354. http://dx.doi.org/10.1016/j.sna.2007.05.010

Rutledge, K. M., \& Gleason, K. K. (1996). Hydrogen in Cvd Diamond Films. Chemical Vapor Deposition, 2(2), 37-43. http://dx.doi.org/10.1002/cvde.19960020203 
Schlapbach, L., \& Züttel, A. (2001). Hydrogen-storage materials for mobile applications. Nature, 414(6861), 353-358. http://dx.doi.org/10.1038/35104634

Serp, P., Madroñero, A., \& Figueiredo, J. L. (1999). Production of vapour-grown carbon fibres: influence of the $\begin{array}{lllll}\text { catalyst precursor and operating conditions. Fuel, } & \text { 78(7), 837-844. }\end{array}$ http://dx.doi.org/10.1016/S0016-2361(98)00216-6

Shaijumon, M. M., \& Ramaprabhu, S. (2005). Studies of yield and nature of carbon nanostructures synthesized by pyrolysis of ferrocene and hydrogen adsorption studies of carbon nanotubes. International Journal of Hydrogen Energy, 30(3), 311-317. http://dx.doi.org/10.1016/j.ijhydene.2004.04.005

Takagi, H., Soneda, Y., Hatori, H., Zhu, Z. H., \& Lu, G. Q. (2007). Effects of Nitric Acid and Heat Treatment on Hydrogen Adsorption of Single-Walled Carbon Nanotubes. Australian Journal of Chemistry, 60(7), 519-523. http://dx.doi.org/10.1071/CH06409

Tóth, J., Garaguly, J., Tompa, K., Lovas, A., \& Varga, L. K. (1996). Hydrogen uptake monitored by resistance change in amorphous $\mathrm{Zr}_{33} \mathrm{Ni}_{67}$ alloy. International Journal of Hydrogen Energy, 21(11-12), 1039-1040. http://dx.doi.org/10.1016/S0360-3199(96)00047-X

Vinke, P., van der Eijk, M., Verbree, M., Voskamp, A. F., \& van Bekkum, H. (1994). Modification of the surfaces of a gas-activated carbon and a chemically activated carbon with nitric acid, hypochlorite, and ammonia. Carbon, 32(4), 675-686. http://dx.doi.org/10.1016/0008-6223(94)90089-2

Voit, A. P., Evard, E. A., \& Gabis, I. E. (2002). Effect of Sorbed Hydrogen on the Conductivity of Nanoporous Carbon. Materials Science, 38(4), 570-575. http://dx.doi.org/10.1023/A:1022970818229

Waqar, Z. (2007). Hydrogen accumulation in graphite and etching of graphite on hydrogen desorption. Journal of Materials Science, 42(4), 1169-1176. http://dx.doi.org/10.1007/s10853-006-1453-1

Yushin, G., Dash, R., Jagiello, J., Fisher, J. E., \& Gogotsi, Y. (2006). Carbide-Derived Carbons: Effect of Pore Size on Hydrogen Uptake and Heat of Adsorption. Advanced Functional Materials, 16(17), 2288-2293. http://dx.doi.org/10.1002/adfm.200500830

Zhang, J., Zou, H., Qing, Q., Yang, Y., Li, Q., Liu, Z., Guo, X., \& Du, Z. (2003). Effect of Chemical Oxidation on the Structure of Single-Walled Carbon Nanotubes. Journal of Physical Chemistry B, 107(16), 3712-3718. http://dx.doi.org/10.1021/jp027500u

Zubizarreta, L., Arenillas, A., \& Pis, J. J. (2009). Carbon materials for $\mathrm{H}_{2}$ storage. International Journal of Hydrogen Energy, 34(10), 4575-4581. http://dx.doi.org/10.1016/j.jhydene.2008.07.112 